\title{
ANÁLISIS HISTORIOGRÁFICO DE LA JORNADA DEL FOSO
}

\author{
María Crego Gómez \\ Universidad Pablo de Olavide de Sevilla
}

\begin{abstract}
Resumen: Gracias a la aparición del ms. correspondiente al segundo fragmento (M2-b) del Muqtabis de Ibn Ḥayyān (s. XI) es posible llevar a cabo el estudio historiográfico completo de uno de los relatos más célebres del período emiral andalusí, el conocido como «ornada del Foso». El presente trabajo aborda el cotejo intertextual de las diferentes versiones conocidas hasta el momento en las crónicas árabes.
\end{abstract}

Palabras clave: Ibn Ḥayyān, Muqtabis, Toledo, historiografía.

Abstract: The publication of the manuscript corresponding to the second piece of the Muqtabis by Ibn Hayyān (11th century) has allowed to implement the complete historiographical analysis of one of the most famous stories of the Andalusian emirate, the well-known «Jornada del Foso». The present work focuses on the intertextual collation of different versions found in Arabic chronicles for the moment.

Keywords: Ibn Hayyān, Muqtabis, Toledo, historiography.

\section{INTRODUCCIÓN}

La aparición de la segunda parte del tomo II del Muqtabis (M2-b) ${ }^{1}$ ha permitido conocer los textos que Ibn Ḥayyān compiló acerca de la noticia más destacada - junto con el relato de la conquista definitiva de la ciudad por al-Nāșir en el año 320 (932) - que los cronistas asocian con la historia del Toledo islámico durante el período Omeya: la conocida tradicionalmente como «Jornada del Foso». Según las crónicas, se trató de un suceso acaecido en tiempos del emir alḤakam I y por él perdieron la vida los principales de la ciudad, en un intento por

1 Ben Haián de Córdoba, Muqtabis II. Anales de los Emires de Córdoba Alhaquém I (180-206 H/796-822 J. C.) y Abderramán II (206-232/822-847), ed. fac. de un ms. árabe de la R.A. H. (Legado Emilio García Gómez) J. Vallvé Bermejo, Madrid, R.A.H., 1999. A partir de ahora citaré esta obra como M2-b. Edición completa del texto árabe: M. 'A. Makkī, Al-sifr al-țānī min Kitāb al-Muqtabas, al-Riyad, 2003. Traducción completa al español: M. 'A. Makkī y F. Corriente (trad., notas e índices), Crónica de los emires Alhakam I y Ádarrahmān II entre los años 796 y 847 [Almuqtabis II-1], Zaragoza, Instituto de Estudios Islámicos y del Oriente Próximo, 2001. 
parte del monarca de aplacar la actitud levantisca de sus habitantes ${ }^{2}$. Las distintas versiones coinciden en presentar como protagonista y responsable de la estratagema llevada a cabo a 'Amrūs b. Yūsuf, elegido por su condición de muladí para desarrollar el plan ideado por el emir. Sin embargo, después veremos cómo es posible diferenciar dos familias de textos. En algunos relatos 'Amrūs se presenta como el único artífice del engaño urdido contra los toledanos, mientras que en otros aparece un segundo personaje que pasa a desempeñar también su papel en la trama. Se trata del príncipe 'Abd al-Raḥmān, futuro emir de al-Andalus, hijo de al-Ḥakam.

El relato, recogido en versiones de diferente extensión, tiene como motivo principal un banquete celebrado en la fortaleza de la ciudad. A él son invitados los notables toledanos, que acudirán sin sospechar que, una vez dentro del recinto, serán degollados junto a una fosa excavada en el interior. Según algunas versiones, la terrible matanza fue descubierta por alguno de los invitados y sirvió de escarmiento a la población, que se mantuvo sumisa por algún tiempo. En las páginas que siguen presento el estudio historiográfico de los relatos que han llegado hasta nosotros acerca de este episodio, para lo cual he recurrido al cotejo intertextual de las diferentes versiones conservadas.

\section{VERSIONES CONOCIDAS ANTES DE LA PUBLICACIÓN DEL MS. M2-B}

Hasta la aparición de este fragmento del Muqtabis, contábamos con nueve versiones del relato, la más antigua de las cuales pertenecía a Ibn al-Qūtịya (m. 367/977) y está recogida en su Tảrìj iftitāh al-Andalus ${ }^{3}$. Las siguientes por orden cronológico son las de Ibn al-Ațìr (m. 630/1233) y al-Nuwayrī̄ (m. 733/1333). La obra de este último, Nibāyat al-arab, guarda una estrecha relación con el Kämil, de tal manera que hemos podido comprobar cómo al-Nuwayrī, también en este caso, copia a Ibn al-Ațīr y, al igual que él, recoge dos noticias diferentes alusivas a este suceso y fechadas con distinta data. Una de ellas se asemeja a la noticia que encontramos en Al-Bayān de Ibn 'Idarī' (m. 720/1320), la cuarta fuente que informa de la «ornada del Foso». Las cinco restantes son

2 Véase el contexto histórico de esta noticia en M. Crego Gómez, Toledo en época Omeya (s. VIII-IX), Toledo, Diputación de Toledo, 2007, pp. 38-79.

3 Historia de la conquista de España por Abenalcotía el Cordobés, ed. y trad. J. Ribera, Madrid, 1926, pp. 45-49. He cotejado este texto con el del ms. del Tárīj iftitāh al-Andalus, al que tuve acceso a través del Archivo Digital de Manuscritos Árabes creado por el grupo de Historia del Islam de la Escuela de Estudios Árabes (C.S.I.C.) de Granada.

4 Al-Kämil fì l-ta'rīj, Beirut, 1979, vol. VI, p. 158 y pp. 199-201.

5 Nihāyat al-arab fì funūn al-adab, El Cairo, 1980, vol. XXIII, p. 361 y pp. 365-367.

6 Histoire de l'Afrique du Nord et de l'Espagne musulmane intitulée 'Kitāb al-Bayān al-Mugrib' par Ibn 'Id̄àrì al-Marrākušì et fragments de la chronique de 'Arīb d'après l'édition de 1848-1851 de $R$. Dozy et de nouveaux manuscrits, ed. G. S. Colin y É. Lévi-Provençal, Leiden, 1948-51, (Bayān II), pp. 69-70. 
al-Dahabīi (m. 748/1348), Ibn Faḍl Allāh al-'Umari8 (m. 749/1349), Ibn alJațīb ${ }^{9}$ (m. 776/1375), Ibn Jaldūn ${ }^{10}$ (m. 784/1382) y el Dikr bilād al-Andalus ${ }^{11}$ (s. XIV o XV). Además de las anteriores, existen otras fuentes, fundamentales para conocer la historia de al-Andalus, que, a pesar de recoger en sus páginas el período correspondiente al emirato de al-Hakam I, no dan cuenta de este suceso. Entre ellas están el Kitāb al-iktifä', de Ibn al-Kardabūs, la Hulla de Ibn alAbbār, el Fath al-Andalus, los Ajbār Maŷmǘa o el Naf̣̂ al-Ṭ̂̀b de al-Maqqarī.

A través del análisis y cotejo de las diferentes versiones era posible establecer, en primer lugar, una relación entre el relato de Ibn al-Qūtiyya y uno de los dos que aparecen en la obra de Ibn al-Atìr, que mantienen un paralelismo continuo en el contenido, sin que podamos decir lo mismo de la forma. Relatos extensos los dos, era evidente que, bien compartían alguna fuente común o bien, dada la distancia temporal que separa a ambos autores, Ibn al-Atīr pudo emplear otra fuente que, a su vez, se había servido de la versión de Ibn al-Qūtịya. Pero Ibn al-Atīir recoge una segunda versión, más breve, que debe proceder de otra fuente. En Al-Bayān de Ibn 'Iḍārī encontramos una noticia alusiva al Foso de similar extensión a ésta de Ibn al-Ațìr, entre las cuales debe existir alguna relación, pues es evidente que una gran parte de este fragmento guarda muchas similitudes con el texto del Kämil, si bien parece que algunos elementos del relato no proceden de Ibn al-Ațîr. Respecto a las versiones de al-Nuwayrī e Ibn Jaldūn, es clara su correspondencia con el relato de Ibn al-Atîir. En el caso de al-Nuwayrī, su noticia procede íntegramente de este último, mientras que el relato de Ibn Jaldūn, más breve, parece extractar el texto de Ibn al-Ațìr. Al-Dahabī, al-'Umarī e Ibn al-Jațîb transmiten un relato alusivo a la «Jornada del Foso» que entronca con la versión que aparece en el Tárīj iftitāh al-Andalus de Ibn al-Qūtịya, quien, sin embargo, no puede ser fuente directa de estos autores. La versión del Dikr biläd al-Andalus, finalmente, presenta ciertas similitudes con todos estos relatos que parecen tener su origen en Ibn al-Qüțiyya; sin embargo, hay otros elementos cuya procedencia desconocemos y, si a esto sumamos el hecho de que se trata de un texto muy breve, resulta difícil explicar su origen.

Estas consideraciones iniciales responden a un primer análisis de las versiones conocidas hasta el momento acerca de la «Jornada del Foso». Como hemos podido comprobar, en este listado de fuentes existe un vacío entre la que data de fecha más temprana, Ibn al-Qūtịya (s. X), y la siguiente, Ibn al-Ațīr (s. XIII). Para solventar las dudas que plantea la reconstrucción historiográfica

7 Siyar a 'lām al-nubalā', Beirut, 1986, vol. VIII, pp. 259-260.

8 Routes towards insight into the capital empires. Masālik al-abșār fi mamālik al-amșār, ed. F. Sezgin, Frankfurt am Main, 1988, vol. II, pp. 28-30.

9 Kitāb a'māl al-a 'àm. Histoire de l'Espagne musulmane extraite du 'Kitāb a'māl al-a 'àm', ed., introd. e índices É. Lévi-Provençal, Rabat, 1934, pp. 14-15.

10 Kitāb al-íibar, Beirut, 1867, vol. IV, pp. 125-127.

11 Dikr bilād al-Andalus. Una descripción anónima de al-Andalus, ed. L. Molina, Madrid, 1983, p. 132 . 
antes expuesta, así como para confirmar los datos obtenidos de ese cotejo intertextual, sería muy interesante tratar de desvelar cómo se relató este suceso en los siglos X y XI, período en que elaboraron sus obras al-Rāzī, 'Arib b. Sa īid e Ibn Ḥayyān, entre otros. Precisamente, la aparición del manuscrito M2-b viene a cubrir en buena medida ese espacio temporal, pues Ibn Ḥayyān compiló los textos históricos anteriores a su tiempo y, gracias a esa labor, hoy conocemos parte de la producción de algunos cronistas cuyas obras se han perdido. A continuación profundizaremos en las relaciones historiográficas que mantienen los distintos textos conservados, sirviéndonos de las versiones recogidas en el manuscrito M2-b como referencia fundamental para reconstruir la transmisión de este relato.

\section{RELATOS INCLUIDOS EN EL MS. M2-B}

Ya sabíamos de la existencia de una versión del relato de la «ornada del Foso» en la obra de Ibn Ḥayyān antes de la publicación del manuscrito, porque É. Lévi-Provençal se hizo eco de ella al describir este suceso ${ }^{12}$. Ahora bien, el arabista francés también empleó las versiones de Ibn al-Ațīr, Ibn 'Id̄ārī e Ibn Jaldūn y no especificó a quién pertenecían los datos con los que elaboró su propia crónica de tan célebre acontecimiento. Hoy sabemos que Ibn Ḥayyān recogió no una, sino cuatro versiones del relato, lo que, por otra parte, responde a la costumbre del historiador cordobés de incorporar a su obra todos los textos conocidos acerca de un mismo suceso.

\subsection{AHMAD AL-RĀZII ${ }^{13}$}

Su relato, el primero de los cuatro, aparece tras el encabezamiento del capítulo correspondiente al año 181 (797-798). La crónica de al-Rāzī alusiva a este año comienza con la noticia de la sublevación en Zaragoza de Buhlūl b. Abī 1-Haŷŷâŷy, rebelión que también apoyarían dos generales del emir Hišām I, 'Abd al-Karīm y 'Abd al-Malik b. Mugịt, así como 'Abd Allāh al-Balansī, tío de alHakam I. Más tarde tendremos que volver sobre esta noticia, porque algunos autores posteriores a al-Rāzì también hablan de ella y lo hacen precisamente antes del relato de la «Jornada del Foso», como ocurre en la presente versión, lo cual ayuda a establecer la relación existente entre esos cronistas y el historiador cordobés del s.X.

Inmediatamente después, al-Rāzī menciona la destitución del gobernador de Toledo que tuvo lugar en esa misma fecha y el nombramiento de uno nuevo. Se trata de una información muy valiosa porque es la primera vez que tenemos noticia de estos dos personajes. El emir al-Ḥakam destituyó a 'Abd Rabb b. Zurayq

12 Historia de España. Dirigida por R. Menéndez Pidal. IV: España musulmana hasta la caída del califato de Córdoba, Madrid, 1967 (3a ed.), pp. 103-104.

13 M2-b, op. cit., pp. 9-10 (92 $\left.\mathrm{r}^{\mathrm{o}}-92 \mathrm{v}^{\mathrm{o}}\right)$; Crónica de los emires..., op. cit., pp. 27-28. 
y nombró gobernador de la ciudad a 'Abd al-'Azīz b. Ḥassān, quien no debía de contar con el apoyo de los toledanos, pues la población se apresuró a rebelarse. $\mathrm{Al}$ frente de esta sublevación se encontraba un tal 'Ubayd Allāh b. Jumayr. El emir ordenó luego a 'Amrūs b. Yūsuf, por aquel entonces señor de Talavera, que combatiera a los rebeldes y éste se las ingenió para que un grupo de toledanos que debían de gozar de cierto prestigio en la ciudad traicionase a 'Ubayd Allāh. Se trataba de los Banū Majšì, de los que apenas sabemos nada, tan sólo que debían de mantener alguna disputa con los bereberes de Talavera, pues, una vez que acabaron con 'Ubayd Allāh y acudieron a esta ciudad buscando la protección de 'Amrūs, fueron asesinados por aquéllos. Tendremos que esperar a consultar el relato de Ibn Jaldūn para conocer algún otro detalle acerca de este enfrentamiento entre los dos grupos. 'Amrūs entró en Toledo después de haberse ganado la confianza de la población y, tras levantar un recinto fortificado que serviría de alojamiento para él y su tropa, invitó a los notables toledanos a un banquete. Les indicó que entraran por una puerta y salieran por otra, de manera que, una vez dentro, acabó con ellos al pie de una fosa excavada en el interior. Cuando ya habían muerto muchos de ellos, los que aún quedaban en el exterior se dieron cuenta de lo que ocurría y pudieron huir. 'Amrūs acabó con حز (hizām) para referirse al recinto amurallado levantado en Toledo por el general del emir al-Ḥakam ${ }^{14}$.

\section{$3.2 \bar{I}_{S \grave{A}} A L-R \bar{A} Z \bar{I}{ }^{15}$}

En este caso, aparece consignada la fuente: Muhammad b. 'İsà al-Ma'āfirīi16. El texto está también incluido en el capítulo correspondiente al año 181 y se trata de la única versión que presenta al príncipe 'Abd al-Raḥmān, futuro emir de al-Andalus, como gobernador de la ciudad y responsable de la matanza. Es, además, el único texto, junto con el de al-'Umarī, en el que se menciona la circuncisión de los hijos pequeños del emir al-Ḥakam como excusa para celebrar un banquete en Toledo. El monarca escribe a su hijo informándole de que, con motivo de la circuncisión de sus hermanos, ha celebrado un gran festín en Córdoba y le transmite su deseo de que los toledanos participen también de los festejos. Le ordena preparar en Toledo un banquete al que habrá de invitar a los notables de la ciudad. Cuando éstos acudan al alcázar, serán asesinados y nadie se dará cuenta de la terrible matanza hasta que los cuerpos de las víctimas rebasen el borde de la fosa a la que habían sido arrojados.

14 Sobre las noticias del ms. M2-b acerca del alcázar y el hizām toledanos, véase M. Crego, Toledo en época Omeya..., op. cit., pp. 141-145.

15 M2-b, op. cit., p. 10 (92vo); Crónica de los emires..., op. cit., pp. 28-29.

16 Sobre este alfaquí, véase M. Marín, "Nómina de sabios de al-Andalus (93-350/711-961)", E. O.B.A., I (1988), no 1291, e Ibn Ḥāriț al-Jušanī, Ajbār al-fuqabā’ wa-l-muhadditīn, ed. y est. Ma L. Ávila y L. Molina, Madrid, 1991, no 129. 
En esta versión no encontramos la figura de 'Amrūs ni tampoco el motivo de la construcción de un recinto fortificado, que aparece normalmente asociado a este personaje. Tampoco se mencionan las dos puertas del alcázar que vemos en otras versiones, por las que habrían de entrar y salir los invitados, pero sí un motivo que tan sólo recoge 'İsà al-Rāzī: las flautas y albogues cuyo sonido debía de estar amenizando el festejo y que, al mismo tiempo, impedía oír desde fuera los gritos de las víctimas. Por otra parte, según este relato, el emir habría enviado a su hijo a Toledo como gobernador después de que la población volviera a rendirle obediencia tras un período de revueltas, cuya naturaleza y alcance no se explican aquí. Cuando 'Abd al-Raḥmān se hizo con el control de la ciudad, su padre le ordenó poner en marcha el plan ideado contra los toledanos. En realidad, no tenemos noticias por otras fuentes de que el príncipe 'Abd al-Raḥmān hubiera desempeñado el cargo de gobernador de Toledo antes de su nombramiento como emir. En el Muqtabis sí se menciona, por el contrario, que nació en esta ciudad, siendo su padre gobernador de la misma ${ }^{17}$.

\subsection{AL-QUBBAŠ $\bar{I}^{18}$}

Es muy posible que Ibn Ḥayyān recogiera este relato directamente de alḤasan b. Muḥammad b. Mufarrîy al-Qubbašī. De hecho, utilizó a menudo como fuente para el Muqtabis su obra Kitāb al-ihtifäl fi tárīj a lām al-riȳāl, una composición sobre califas, jueces y alfaquíes. Estamos ante la versión más extensa de todas. Fecha el suceso en el año 190 (805-806), aunque Ibn Ḥayyān incorpore el relato en el capítulo correspondiente al año 181, y se especifica que la «Jornada del Foso» tuvo lugar unos años antes del suceso del Arrabal.

El relato comienza con un extenso párrafo en el que se describe el carácter levantisco de los toledanos, las peculiaridades del emplazamiento de su ciudad y la calidad de sus cultivos. Ante la perseverante actitud de rebeldía de la población, el emir al-Ḥakam llama al muladí 'Amrūs, que en esos momentos se encontraba en la ciudad de Huesca, para que acuda a Toledo en calidad de gobernador, con la esperanza de que se gane la confianza del pueblo. 'Amrūs hace ver a los toledanos que está de su parte y les aconseja construir una alcazaba para aislar a las tropas del emir, que, según dice, son la causa de sus desgracias. El recinto se levanta en el centro de la ciudad y en su interior construye 'Amrūs un palacio con dos puertas, dentro del cual cava un profundo foso. Un tiempo después, el emir ordena a uno de sus gobernadores de la Marca Superior que le envíe por escrito una petición de ayuda contra las tropas enemigas. Con esta excusa, el monarca hace partir a su hijo 'Abd al-Raḥmān al frente de un ejército, que, al pasar junto

17 Al-Muqtabas min anbā' abl al-Andalus li-bn Hayyān al-Qurtubì, ed. M. 'A. Makkī, Beirut, 1973, pp. 17-18. Cito a partir de ahora esta obra como M2-c. Encontramos también recogida esta noticia en otras fuentes, como el Dikr bilād al-Andalus, op. cit., p. 137, e Ibn al-Atīir, op. cit., vol. VI, p. 133.

18 M2-b, op. cit., pp. 10-14 (92vo-94vo); Crónica de los emires..., op. cit., pp. 29-34. 
a la ciudad de Toledo, recibe la noticia de que el enemigo se ha retirado. Aprovecha entonces 'Amrūs la ocasión para convencer a los toledanos de que deben invitar al príncipe a entrar en la ciudad, siguiendo las instrucciones de una carta que le hace llegar un criado del emir. 'Abd al-Raḥmān acepta la invitación y celebra un banquete para agasajar a los toledanos, en cuya preparación se emplean grandes cantidades de alimentos. Los notables de la ciudad acuden a la alcazaba el día del festejo y se les hace entrar por una puerta, haciéndoles ver que saldrán por otra distinta para evitar una aglomeración en el recinto. Una vez en el interior, serán decapitados al borde del foso construido por 'Amrūs a manos de un grupo de soldados armados con espadas. Tan sólo un grupo conseguirá salvar la vida después de que uno de los invitados muestre su extrañeza al no ver salir a nadie de la alcazaba y descubra que la emanación que sale de su interior no procede de la comida sino de los cadáveres de sus compañeros.

Al-Qubbašĩ añade al final que el príncipe 'Abd al-Raḥmān permaneció algún tiempo en Toledo junto a los sucesivos gobernadores del emir; sin embargo, la presencia de una autoridad designada por el poder central quedó de nuevo interrumpida en la ciudad cuando, pasado un tiempo, la población volvió a rebelarse, una vez repuesta de este terrible suceso.

Como hemos podido comprobar, si Aḥmad al-Rāzī sólo hacía referencia a 'Amrūs, al que, por otra parte, presenta como señor de Talavera, y su hijo 'İsà mencionaba únicamente al príncipe 'Abd al-Rahmān, en esta versión de al-Qubbašì vemos reunidos a los dos personajes; 'Amrūs, en este caso, aparece como un leal partidario del emir en la Marca Superior. Este extenso relato resulta ser, como luego veremos, una pieza clave en la cadena historiográfica que puede explicar el origen de esta narración y más tarde lo emplearemos como punto de referencia a la hora de establecer las relaciones intertextuales entre las distintas versiones que han llegado hasta nosotros.

\subsection{IBN AL-QŪṬTYYA ${ }^{19}$}

Ibn Ḥayyān nos dice al principio de este fragmento que Ibn al-Qūtịya relató esta «Jornada del Foso» de la misma manera que lo hizo al-Qubbašì. Así, el autor del Muqtabis sólo transmite el final del relato de Ibn al-Qūtiyya y no todo su texto, porque éste debía de ser similar al que acababa de transcribir atribuido a Ibn Mufarriŷ. Deducimos entonces que Ibn Ḥayyān conoció una versión de Ibn al-Qūṭiyya semejante a la de al-Qubbašìi, de la que únicamente se diferenciaría en el final.

Tenemos constancia de que al-Qubbašĩ (m. después del 430/1038-1039) utilizó como fuente a Ibn al-Qūtiyya. Así aparece recogido explícitamente en una ocasión en el M2- ${ }^{20}$. No obstante, Ibn Ḥayyān no lo menciona en el texto de

19 M2-b, op. cit., pp. 14-15 (94vo-95 ro); Crónica de los emires..., op. cit., pp. 34-35.

20 M2-c, op. cit., p. 41. Véase también Ma L. Ávila, "La fecha de redacción del Muqtabis", AlQantara, V (1984), pp. 99-100. 
este manuscrito, y esto último nos extraña, teniendo en cuenta que el autor del Muqtabis viene citando las fuentes de los textos que compila en su obra, al menos por lo que respecta al relato del Foso ${ }^{21}$.

Ibn Ḥayyān no transcribe el relato completo de Ibn al-Qūtịyya y, en consecuencia, desconocemos datos como la fecha o detalles alusivos a la celebración del banquete. En cualquier caso, debemos suponer que esa información es similar a la que aparece en la versión de al-Qubbašǐ. Lo que Ibn al-Qūtịya añadió en su versión que difiere del relato de este último es, en primer lugar, el parpadeo que a partir del suceso tuvo el príncipe 'Abd al-Raḥmān en sus ojos producido por el brillo de las espadas utilizadas el día de la matanza. Luego describe cómo uno de los invitados que se acercó al alcázar comenzó a sospechar que algo grave ocurría, una vez que la matanza había alcanzado ya a más de cinco mil personas. Este personaje pronunció entonces unas palabras atribuidas a Quss b. Sā'ida ${ }^{22}$ acerca de los muertos. La existencia real de este poeta y sabio, considerado el orador más importante de las tribus de época preislámica, parece estar avalada por un hadìt según el cual el Profeta habría preguntado por Quss y, al saber que había muerto, recordó uno de sus discursos, que él mismo habría escuchado en 'Ukāz, el lugar cercano a La Meca donde se celebraban torneos literarios. Se trata de una tradición dudosa ${ }^{23}$ pero, en todo caso, parece que de este texto procede la frase pronunciada por el personaje toledano, que coincide literalmente con la que aparece en el relato de la tradición:

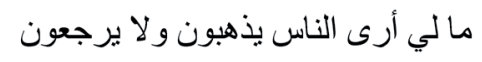

«¿Cómo es que veo que la gente va pero no regresa?»

El relato de Ibn al-Qūtịya continúa con la advertencia que este personaje toledano hizo a los que aún no habían entrado en el alcázar, maldiciendo al pueblo de Toledo y haciendo ver que la emanación que se elevaba por encima del recinto no procedía de la comida, sino de la sangre de los muertos. Ibn al-Qūțiyya termina afirmando que los toledanos se mantuvieron sumisos desde entonces y hasta el comienzo del emirato de Muhammad I. Luego se rebelarían de nuevo y sólo volverían a mostrar obediencia bajo la autoridad de 'Abd al-Raḥmān III al-Nāṣir.

21 No hemos encontrado a lo largo de todo el ms. M2-b una referencia explícita que indique que al-Qubbašĩ utilizó la obra de Ibn al-Qūțiyya como fuente. Únicamente en una ocasión podemos intuirlo: hay un pequeño fragmento atribuido a Ibn al-Qūtiyya acerca de los andalusíes que viajaron hasta Alejandría y luego a Creta que aparece incluido dentro de la versión de Qubbašĩ sobre el motín del Arrabal de Córdoba; M2-b, op. cit., pp. 44-45 (109vo-110ro). No obstante, no podemos afirmar con seguridad que Ibn Ḥayyān tomara este pasaje a través de al-Qubbašī.

22 Véase Al-Ŷāhiz, Al-Bayān wa l-tabyīn, El Cairo, s.d., p. 20, y sobre este personaje, C. Pellat, "Kuss b. Sā‘ida”, $E I^{2}$, V, pp. 532-533, y L. Cheikho, Kitāb šu'arä’’ al-nașraniyya, Beirut, 1890 1891, vol. 1, pp. 211-218.

23 Acerca de este hadiț , véase C. Pellat, art. cit. El texto árabe puede localizarse, entre otras fuentes, en Abū 1-Faraŷ al-Iṣbahāni, Kitāb al-agānī, Bulaq, 1868-1869, vol. V (t. XIV), pp. 41-42. 
Efectivamente, el final de esta versión difiere del final del relato de al-Qubbašī. Coinciden en la referencia a la advertencia que hace uno de los invitados y en la de la emanación de la sangre, pero al-Qubbašĩ no menciona el parpadeo del príncipe ni las palabras de Quss b. Sā‘ida y no cita a al-Nāṣir. Ibn al-Qūțiyya, por su parte, no dice que 'Abd al-Rahmān residiera por un tiempo en Toledo después del suceso. La versión que ahora nos ocupa, junto con la de Ahmad alRāzī y la de su hijo 'Īsà, son las más antiguas que conocemos acerca de esta «Jornada del Foso». A ellas debemos sumar el relato que aparece en el Tárīj iftitāh al-Andalus. Cuestión aparte será cotejar este último relato con el que aparece en el Muqtabis atribuido a Ibn al-Qūtịya, asunto que trataré más adelante.

\section{ESTUDIO HISTORIOGRÁFICO}

A la vista de las trece versiones que han llegado hasta nosotros acerca de esta «Jornada del Foso», y tras un estudio exhaustivo de las relaciones intertextuales entre los diferentes relatos, es evidente que existen dos grandes familias de textos alusivos a este suceso, caracterizadas por elementos claramente diferenciadores:

Un grupo de textos presenta como desencadenante del suceso la rebelión de un personaje toledano, 'Ubayd Allāh b. Jumayr — que recibirá distintos nombres, según la versión-, al que se enfrentará 'Amrūs b. Yūsuf, general del emir al-Ḥakam asentado en Talavera. 'Amrūs se servirá de una familia toledana, la de los Banū Majš̄i, para acabar con 'Ubayd Allāh. Sin embargo, aquellos encontrarán también la muerte al acudir más tarde a Talavera junto a 'Amrūs y ser asesinados por los bereberes de la ciudad. El general entra luego en Toledo y decide construir un recinto fortificado. Allí celebrará un banquete en honor de los toledanos, en el transcurso del cual acabará con los notables de la ciudad junto a un profundo foso excavado en el interior. La noticia está fechada en el año 181 (797-798) y siempre aparece asociada al relato de la rebelión de Buhlūl b. Abī 1-Ḥaŷȳâŷ en Zaragoza, ocurrida el mismo año.

La segunda familia de textos, por lo general más extensos que los anteriores, relata cómo el emir al-Ḥakam decide enviar a 'Amrūs b. Yūsuf, por aquel entonces en la Marca Superior, como gobernador a Toledo para aplacar la rebeldía de sus habitantes. El emir tenía la esperanza, dado que 'Amrūs era de origen muladí, de que la población se pusiera de su parte y confiara en él, de modo que fuera más fácil llevar a cabo el plan ideado contra ellos. Ya en Toledo, 'Amrūs convence a sus habitantes de que es oportuno levantar una alcazaba en donde aislar a los mercenarios del emir. Allí construirá un profundo foso. Mientras tanto, el monarca hace que desde la Marca Superior le sea enviada una petición de auxilio contra el enemigo cristiano. Hace partir en expedición a su hijo 'Abd al-Raḥmān con esa excusa, pero al pasar precisamente junto a Toledo este último recibe la noticia de que el enemigo se ha retirado. Los toledanos invitan entonces al príncipe a entrar en la ciudad y, con motivo de esta visita, se celebra 
un banquete en la fortaleza de 'Amrūs. Los notables acudirán a la celebración el día fijado para el evento y allí serán asesinados por los hombres del emir. Según algunas versiones, uno de los invitados se percata por el vapor de la sangre de que han asesinado a los que ya habían entrado en el recinto y avisa al resto, que logra salvar la vida. Otras añaden también que la terrible visión de la matanza provocó un parpadeo en la vista del príncipe 'Abd al-Raḥmān, lesión que le duró toda la vida. Por último, únicamente en uno de los textos se menciona el nombre de otro personaje rebelde, el poeta Girbīb, tras cuya muerte, según Ibn al-Qūtiyya, tuvo lugar este suceso del Foso. La mayor parte de estas versiones da como fecha del acontecimiento el año 191 (806-807).

\subsection{Primera tradición textual}

Aḥmad al-Rāzī es el autor más antiguo que recoge la primera versión de este relato, en la que, como ya sabemos, no aparece el príncipe 'Abd al-Raḥmān. Tal y como hemos descrito antes, su texto viene precedido de la noticia de la sublevación de Buhlūl en Zaragoza e incluye los nombres, hasta ahora desconocidos, de dos gobernadores de Toledo.

Pues bien, ya he señalado que Ibn al-Ațīr introdujo en su obra dos noticias diferentes que aludían a la «Jornada del Foso». Una de ellas, la fechada en el año 181, aunque más breve, guarda muchas similitudes con el relato de Aḥmad alRāzì que encontramos en el manuscrito del Muqtabis. Coinciden en señalar la rebelión de Buhlūl en Zaragoza y luego ambos relatan cómo 'Amrūs combate a 'Ubayd con la ayuda de los Banū Majšì. También coinciden en el número de muertos y en la fecha. Sin embargo, en algunos datos difieren y a veces las expresiones utilizadas no son las mismas. Ibn al-Atīir no nombra a los hijos de 'Abd al-Wāḥid b. Mugìt, que, según al-Rāzī, habían apoyado a Buhlūl; por otro lado, Ibn al-A tīir no menciona a los gobernadores designados por al-Ḥakam para Toledo y al-Rāzì llama al rebelde toledano 'Ubayd Allāh b. Jumayr, mientras que Ibn al-Atīir le da el nombre de 'Ubayda b. Humayd. Estos y otros detalles, como el hecho de que el autor del Kämil no hable de ningún foso, aunque mencione la matanza, hacen pensar que la versión de Ibn al-Atīir no procede directamente del relato de al-Rāzī que conocemos. Es posible que existiera más de una versión de Aḥmad al-Rāzī y que Ibn al-Atīr conociera una distinta de la que nos ha llegado a través del M2-b. Pero también debemos considerar otra posibilidad y es que Ibn al-Atîir hubiera conocido este relato por otro autor u obra. Si su noticia no procede de al-Rāzì ni tampoco tiene relación con la otra familia de textos, debe tener su origen en un texto semejante al del historiador cordobés del s. $\mathrm{X}^{24}$. De momento, por lo tanto, tan sólo podemos afirmar con certeza que

24 Debemos recordar que no se ha conservado ningún relato alusivo al Foso de 'Arīb b. Sa'îd, quien quizás lo introdujo en su obra y cuyo texto sería, posiblemente, similar al de al-Rāzī. J. Castilla ya señaló que es muy posible que 'Arīb conociera personalmente a al-Rāzī y que utilizara su obra, pero, sobre todo, que ambos pudieron disponer de la misma documentación de palacio 
los textos de al-Rāzī e Ibn al-Ațīr guardan muchas similitudes y pertenecen a la misma familia.

Hay una tercera versión que también pertenece a este grupo de textos: la de Ibn 'Iḍārī. Fechada en el año 181, recoge, al igual que las dos anteriores, el levantamiento en la Marca Superior y la revuelta del rebelde toledano. El análisis de este texto permite comprobar que el primer fragmento, el que alude a la rebelión de Buhlūl, se corresponde claramente con el primero de Ibn al-Atīr. Parece claro que hay un paralelismo entre ambos textos:

Ibn al-Atīir

$$
\begin{aligned}
& \text { وفي هذه السنة خالف بَهُلْول (sic) بن مرزوق، المعروف بأبي الحجّاج، في ناحية الثخر من بلاد }
\end{aligned}
$$

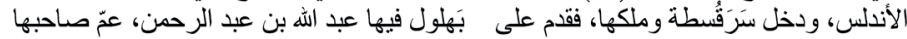

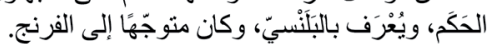

«Este año se rebeló Buhlūl b. Marzūq, conocido como Abū 1-Ḥaŷȳâŷy, en la zona de la Marca, en el país de al-Andalus. Entró en Zaragoza y se apoderó de ella. Allí acudió junto a Buhlūl 'Abd Allāh b. 'Abd alRaḥmān, tío del soberano al-Ḥakam, conocido como «el Valenciano», que se dirigía a Francia».

Ibn 'Iḍārī

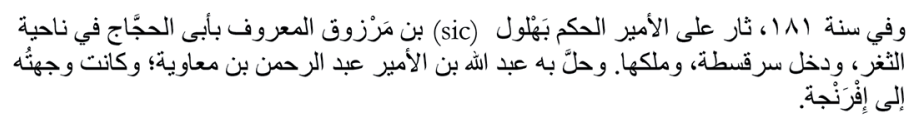

«En el año 181 Buhlūl b. Marzūq, conocido como Abū l-Hâŷyâŷ, se sublevó contra el emir al-Ḥakam en la zona de la Marca, entró en Zaragoza y se apoderó de ella. 'Abd Allāh, hijo del emir 'Abd alRaḥmān b. Mu'āwiya, que se dirigía hacia Francia, se estableció junto a él».

La segunda parte del relato presenta más problemas. Aquí hay elementos que sólo aparecen en la versión de Aḥmad al-Rāzì y otros que sólo encontramos en la de Ibn al-Ațîr. Hay algo fundamental que Ibn 'Iḍārī e Ibn al-Ațīr comparten y es que no mencionan la fosa, referencia que sí aparece en al-Rāzì. También coincide con Ibn al-Atīir en el nombre del rebelde toledano, que es exactamente igual en ambos -'Ubayda b. Ḥumayd-, mientras que al-Rāzī presenta una ligera variación. Respecto a la versión de al-Rāzīi, Ibn 'Iḍārī comparte con él expresiones que se asemejan en la forma, como:

acerca del período del Emirato, lo que haría que sus composiciones se asemejaran; véase La crónica de Arìb sobre al-Andalus, Granada, 1992, p. 72. 
Al-Rāzì

فأعمل عمروس الحيلة في استلطان أهل طليطلة

«Amrūs se valió de artimañas para ganarse el favor de los toledanos».

Ibn 'Iḍārī

$$
\text { ثم إن عمروس أعمل جهده في استجلاب أهل طليطلة }
$$

«Después 'Amrūs dedicó todo su esfuerzo a atraerse a los toledanos».

Al-Rāzī

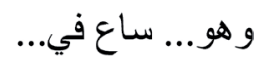

«(...) lo que pretendía ... era...».

Ibn ‘Iḍ̄rī̄

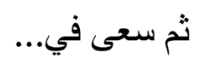

«Luego se propuso...».

Al mismo tiempo, es posible encontrar frases que no proceden ni de la versión de al-Rāzī ni de la del autor del Kāmil:

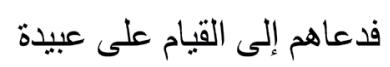

«Les incitó a levantarse contra 'Ubayda».

$$
\text { وو عدهم على ذلك بمثوبة جليلة من الأميز }
$$

«Les prometió a cambio de esto una gran recompensa de parte del emir».

\section{فأحكمه و أثقن أمره}

«Fortificó [el alcázar] y lo acondicionó».

Sería lícito pensar que Ibn 'Iḍārī resumió deliberadamente el texto de alRāzì que aparece en la obra de Ibn Ḥayyān, eliminando grandes frases y seleccionando sólo los párrafos que le interesaban. Sin embargo, teniendo en cuenta que en su relato también hay elementos que no proceden de esa versión, hemos de suponer que pudo conocer el texto a través de otro autor u obra en la que el 
relato aparecía ya resumido. Caben otras tres posibilidades: la primera, que Ibn 'Iḍārī elaborara su versión utilizando al mismo tiempo el relato de Ibn al-Ațīr, que, como hemos visto, es semejante al de al-Rāzì, y el de este último (bien el que aparece en el M2-b u otro semejante en el que, por ejemplo, no se mencionaba el foso); en segundo lugar, es posible que el autor de Al-Bayān al-Mugrib conociera este relato a través de una versión de al-Rāzī distinta de la que nos ha llegado a través del M2-b; finalmente, hemos de considerar una tercera opción, y es el hecho de que Ibn 'Iḍārī redactara su versión con un relato diferente al de estos dos autores que venimos nombrando ${ }^{25}$.

Dentro de este primer grupo de textos se incluyen también las versiones de al-Nuwayrī e Ibn Jaldūn. Ambos autores recogen dos noticias diferentes acerca de la presencia de 'Amrūs en Toledo y sólo una de ellas alude al Foso. La otra, fechada en el año 181, relata las sublevaciones de Buhlūl y de 'Ubayda y, en los dos casos, procede de Ibn al-Atīir.

Respecto a al-Nuwayrī, es posible que tomara esta noticia de una versión de Ibn al-Ațir distinta de la que conocemos por el Kāmil, pues, a pesar de que la dependencia es clara, aquí encontramos algún motivo novedoso, como el hecho de que el tío del emir al-Ḥakam, 'Abd Allāh, se instalara en Talavera junto a 'Amrūs, ciudad a la que más tarde acudiría Buhlūl. Es posible también que hubiera completado la noticia con otra fuente. El segundo fragmento, donde se relata la rebelión de 'Ubayda en Toledo, sigue íntegramente el relato de Ibn alAtịir, si bien en él no se incluyen las últimas líneas de éste relativas al Foso, como veremos que ocurre también en la versión de Ibn Jaldūn. Es probable que alNuwayrī estableciera una distinción entre esta noticia acerca de la sublevación de 'Ubayda y la traición de los Banū Majšì, fechada en el año 181, y la noticia que incluye en el capítulo correspondiente al año 191, donde sí aparece el relato de la Jornada, del que luego nos ocuparemos.

Ibn Jaldūn, por último, debió de conocer la versión transmitida originalmente por Aḥmad al-Rāzī a través de Ibn al-Ațìr. La noticia, fechada también en el año 181, aparece extractada, pero en ella hay numerosas frases y expresiones que previsiblemente tienen su origen en el texto de Ibn al-Atīir. Es posible que Ibn Jaldūn resumiera a este último o bien que conociera su relato a través de una versión ligeramente distinta de la del Kämil. Cabe la posibilidad de que le llegara a través de otra fuente que desconocemos. Como en el caso anterior, Ibn Jaldūn menciona la sublevación de 'Ubayda pero no habla del Foso, al que se referirá en una noticia posterior. El relato de Ibn Jaldūn aporta dos datos interesantes que no aparecen en el resto de las fuentes. En primer lugar, afirma que los bereberes de Talavera asesinaron a los Banū Majšì vengando a un secretario (kātib) suyo. El dato es escueto pero valioso porque sólo se da cuenta de él en el

25 Respecto a esta última posibilidad, volvemos a recordar que desconocemos aún si 'Arīb b. Sa ${ }^{\text {īd }}$ elaboró un relato sobre la «Jornada del Foso», pero suponemos que, de ser así, se asemejaría al de al-Rāzī. 
Kitāb al-'ibar y desconocemos su procedencia. Otra información que no aparece en la versión de Ibn al-Ațîr es el nombramiento del hijo de 'Amrūs, Yūsuf, como gobernador de Toledo. Ibn Jaldūn añade que en el año 189 (804-805) los francos atacaron Toledo e hicieron prisionero a Yūsuf ${ }^{26}$. 'Amrūs enviaría entonces a un primo suyo al frente de un ejército que recuperó la ciudad y liberó a su hijo. En realidad, se trata de un error, pues esta información se refiere a la ciudad de Tudela; tanto en la obra de Ibn al-Atīir como en la de al-Nuwayrīi ${ }^{27}$ está documentado el nombramiento de Yūsuf como gobernador de la misma y el suceso que acabo de referiri ${ }^{28}$.

\subsection{Segunda tradición textual}

La segunda familia de textos, que recoge el relato más extenso y, quizás, también el más conocido, debe de tener su origen en la versión de Ibn al-Qūtiyya. Ya conocíamos su relato incluido en el Ta'rīj iftitāh al-Andalus. Pero el manuscrito del Muqtabis nos ha permitido saber que existía otra versión de la «ornada del Foso» atribuida a Ibn al-Qūtịya. Ibn Ḥayyān sólo transcribe el final de la misma, pero es suficiente para que podamos plantear, tras el análisis correspondiente, la hipótesis de que pudieron circular dos versiones distintas de Ibn al-Qūtiyya acerca de la «Jornada del Foso»: la conservada en el Tárij y la que conoció Ibn Ḥayyān. El cotejo de ambos textos muestra que se trata de dos versiones diferentes y que la que aparece en el Ta’rij debe de ser más breve. Esta última, por ejemplo, no recoge las palabras de Quss b. Sā‘ida ni el párrafo final que alude al emir Muhammad y a al-Nāṣir. Las dos versiones se aproximan en el número de muertos y también coinciden en la referencia al parpadeo del príncipe 'Abd al-Raḥmān, aunque no lo describen de la misma manera:

Ibn al-Qūțiyya (Tárij)

$$
\text { و أُتُبت عبد الزحمن بصرَه في السيف فلم تزلْ به غمزة في عينه إلى أن مات }
$$

«(...) los ojos de 'Abd al-Rahmmān, fijos en la espada, no dejaron de parpadearle hasta su muerte».

Ibn al-Qūtịya (M2-b)

الولا عبد الرحمن شاهد مكان تضريب رقاب الققدمين منهم إلى الحفرة بنفسه فلثلثة ما أثار بصره

بريق السيوف بأيدي الخابطين لهم ما عراه شبه العهذة في عينه فلم تفارقه إلى أن مات الثرات

26 Op. cit., vol. IV, p. 126.

${ }^{27}$ Ibn al-Ațīr, op. cit., vol. VI, pp. 187-188; al-Nuwayrī, op. cit., vol. XXIII, pp. 363-364. Ambos autores fechan el suceso en el año 187 (802-803).

$28 \mathrm{Ma}$ J. Viguera recoge este episodio en Aragón musulmán. La presencia del Islam en el valle del Ebro, Zaragoza, 1988 (2a ed.), pp. 76-77. 
«(...) el príncipe 'Abd al-Rahmān vio personalmente el lugar donde fueron decapitados los que llegaron hasta la fosa y, fue tal la intensidad con que le deslumbró el relampagueo de las espadas de los verdugos, que le sobrevino una especie de parpadeo en los ojos que no lo abandonaría hasta su muerte».

Además comparten, entre otras, estas expresiones:

Ibn al-Qūṭiyya (Ta’rij)

$$
\text { و أين أصحابُنا الذين دخلو ا من غدوة فقلِ له على الباب الثانى يخرجون }
$$

«(...) «¿Dónde están nuestros vecinos que entraron por la mañana?». Le dijeron que estaban saliendo por la otra puerta».

Ibn al-Qūtịyya (M2-b)

$$
\text { ما فعل أصحابنا الذين دخلوا منذ الغدوة فقيل له خرجوا من الباب الآخر }
$$

«(...) «ंQué ha sido de nuestros compañeros que llevan ahí desde esta mañana?». Le dijeron que habían salido por la otra puerta».

Ibn al-Qūtịya (Ta,rij)

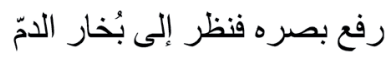

«Elevó la mirada y vio la exhalación que la sangre producía».

Ibn al-Qūtịyya (M2-b)

$$
\text { ورفع رأسه نحو القصر فنظر إلى بخار الدم }
$$

«Levantó la cabeza hacia el alcázar y contempló el vapor producido por la sangre».

Sin embargo, estas semejanzas sólo demuestran que ambos relatos tienen un origen común. En realidad, estamos ante dos versiones distintas y lo interesante será saber cuál de las dos es la que se transmitió a través de los textos posteriores. A la vista de otro de los textos transmitidos por Ibn Ḥayyān en el manuscrito del Muqtabis, el de al-Qubbašī, parece evidente que este relato pudo servir de nexo entre la versión de Ibn al-Qūtịya y las crónicas posteriores. Ya he mencionado más arriba que, a pesar de que Ibn Hayyān aquí no lo indica explícitamente, sabemos con certeza que al-Qubbašĩ utilizó a Ibn al-Qūṭiyya como fuente. El autor del Muqtabis en esta ocasión se limita a señalar que ambos relatos se asemejan, dando a entender que sólo se diferenciarían en el final. Pero es lícito pensar que las semejanzas que observamos al analizar las dos versiones, de las cuales 
doy a continuación algún ejemplo, se deben efectivamente a que al-Qubbašĩ utilizó un texto de Ibn al-Qūțiyya para redactar su relato:

Ibn al-Qūtịyya (M2-b)

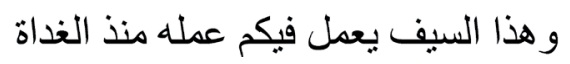

Al-Qubbašī

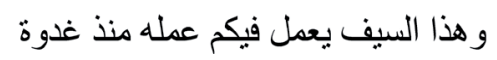

«Esta espada se está empleando a fondo con vosotros desde esta mañana».

Ibn al-Qūtịyya (M2-b)

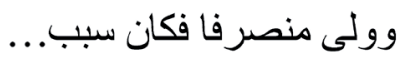

Al-Qubbaši

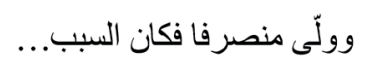

«Dio media vuelta y se alejó. Gracias a esto...».

El final de ambos relatos, como ya se ha dicho, es diferente. Al-Qubbašī no menciona el parpadeo del príncipe ni cita las palabras de Quss b. Sā̄ida. Tampoco alude al emir Muḥammad ni a 'Abd al-Raḥmān III al-Nāṣir.

A la hora de analizar estas versiones, debíamos considerar también la posibilidad de que el texto de al-Qubbašì tuviera su origen en el segundo relato de Ibn al-Qūtịyya, el que nos ha llegado, íntegro, a través del Tảrìj iftităh al-Andalus. Efectivamente, parece que ambos responden a una misma tradición y que la trama de la narración muestra un gran paralelismo. Sin embargo, el texto de Ibn al-Qūtịya es mucho más breve. De hecho, hay largos pasajes en el relato de alQubbašĩ que no están en el de Ibn al-Qūtịya, como el fragmento introductorio que describe el carácter rebelde de los toledanos y las excelencias de sus cultivos. La carta que el emir escribe a la población, por ejemplo, es mucho más extensa en el texto de al-Qubbašĩ. Hay otras diferencias: en la versión de Ibn al-Qūṭiyya la estratagema que debe llevar a cabo 'Amrūs para ganarse la confianza de los toledanos se describe por boca del emir, mientras que en el texto de al-Qubbašĩ es el narrador quien da cuenta de ella. Este último no cita al poeta Girbīb ni menciona el parpadeo del príncipe. En definitiva, sabemos con seguridad que Ibn alQūtịya fue fuente de al-Qubbašì, pero no a través de este relato del Tảrìj iftitāh al-Andalus.

Presento a continuación un fragmento de ambos textos para ilustrar las similitudes entre ellos: 
Ibn al-Qūtịyya (Ta'rij)

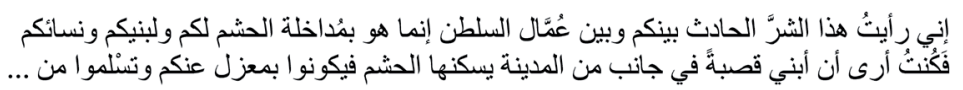

«Creo que los males habidos entre vosotros y los gobernadores enviados por el poder central obedecen al hecho de que los mercenarios se hayan mezclado entre vosotros, entre vuestros hijos y mujeres. $\mathrm{He}$ pensado construir en un lado de la ciudad una alcazaba en la que vivirán los mercenarios, de manera que estén lejos de vosotros y os libréis así de...».

Al-Qubbašī

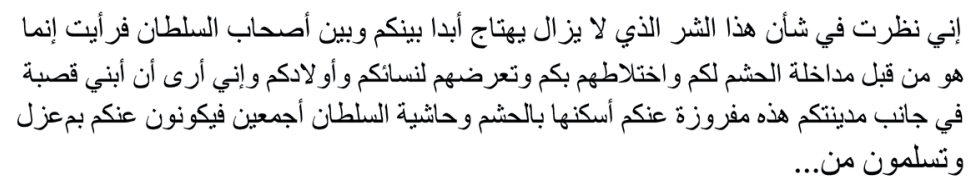

«He reflexionado sobre esta enemistad que nunca deja de suscitarse entre vosotros y los hombres del emir y creo que obedece únicamente a la intromisión de los mercenarios entre vosotros, al trato que mantenéis y al hecho de que atentan contra el honor de vuestras mujeres e hijos. He pensado levantar en un lado de la ciudad una alcazaba, apartada de vosotros, que yo mismo ocuparé junto con todos los mercenarios y el séquito del emir, de manera que estén lejos de vosotros y os libréis así de ...».

Sin duda alguna, al-Qubbašī transmitió con este relato una versión que, en su origen, debe ser atribuida a Ibn al-Qūtịya. El manuscrito M2-b nos ha permitido saber que una de las dos versiones atribuidas a Ibn al-Qūtiyya acerca de la «Jornada del Foso» sería semejante al relato de al-Qubbašī, si bien el final de ambos textos no es el mismo.

A este segundo grupo de textos pertenece también el relato de la «Jornada del Foso", fechado en el año 191 (806-807), de Ibn al-Atīr. Es evidente que existe un claro paralelismo entre esta versión y la de Ibn al-Qūtiyya recogida en el Ta'rīj iftitäh̆ al-Andalus. Sin embargo, aunque los textos tienen, aproximadamente, la misma extensión y su contenido es semejante, Ibn al-Atīir tuvo que tomar el relato de otra fuente. Parece que su texto se aproxima más a la versión de al-Qubbašì, a pesar de que ésta es mucho más detallada. Ambos dan una fecha semejante para el suceso (al-Qubbašì: 190; Ibn al-Ațîr: 191) y coinciden en un dato que no aparece en la versión del Tárīj: el que se refiere al criado que entrega la carta a 'Amrūs cuando los toledanos salen a recibir al príncipe 'Abd alRaḥmān. Por otro lado, las primeras líneas de Ibn al-Ațìr, donde se habla del poderío de la ciudad, de sus riquezas y de la desobediencia de los toledanos, 
recuerdan de alguna manera el primer fragmento del relato de al-Qubbašī, aunque éste es mucho más largo y rico en detalles. Además, los dos no citan a Girbīb ni mencionan el tic o parpadeo del príncipe, pormenores que sí están presentes en la versión del Ta'rīj.

No obstante, aún debíamos cotejar el texto de Ibn al-Atīir con el final del relato de Ibn al-Qūtiyya que aparece en el M2-b. Entre ambos existen grandes diferencias de contenido, pues Ibn al-Atīr no menciona el defecto en la vista del príncipe, las palabras de Quss o el dato relativo a la emanación de la sangre. Pero sí coinciden en dar el mismo número de muertos (más de cinco mil) y en un fragmento cuya similitud no debe pasar desapercibida:

Ibn al-Qūtịya (M2-b)

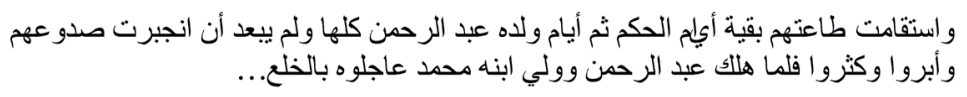

«Se mantuvieron sumisos durante el resto del reinado de al-Hakam y luego a lo largo de todo el de su hijo 'Abd al-Rahmmān. Es posible que, mientras tanto, se repusieran de sus desgracias, se recuperaran y crecieran en número, pues, cuando 'Abd al-Raḥmān murió y subió al poder su hijo Muhammad, inmediatamente le negaron obediencia...”.

Ibn al-Atīir

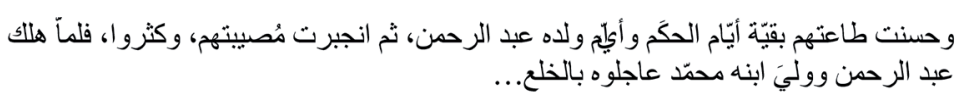

«Demostraron sincera obediencia durante el resto del reinado de alḤakam y a lo largo del de su hijo 'Abd al-Raḥmān. Más tarde, se recuperaron del percance y se hicieron más numerosos, de manera que, al morir 'Abd al-Raḥmān y acceder al trono su hijo Muḥammad, en seguida le negaron obediencia...».

La semejanza de estas líneas, que no aparecen en la versión de al-Qubbašī, nos hace pensar que Ibn al-Atîir habría compuesto su texto sintetizando los datos incluidos en las versiones de al-Qubbašĩ y de Ibn al-Qūṭiyya incorporadas en el Muqtabis. Con respecto a la primera de ellas, que es la que se conserva completa, el texto de Ibn al-Atīr es mucho más breve y este último no copia de al-Qubbašì de forma literal. La versión de Ibn al-Ațìr, por tanto, resulta ser un resumen, elaborado a partir del Muqtabis, del relato original de Ibn al-Qūtịya del que venimos hablando ${ }^{29}$.

29 L. Molina ya indicó no solamente que Ibn al-Atīi utilizó como fuente el Muqtabis de Ibn Ḥayān sino que, posiblemente, lo hizo a través de un resumen del mismo; véase "Un relato de la conquista de al-Andalus", Al-Qanțara, XIX (1998), p. 64. 
Por otro lado, al igual que ocurría en el caso del primer grupo de textos, la noticia alusiva al Foso que transmiten tanto al-Nuwayrī como Ibn Jaldūn, fechada en el año 191, procede de Ibn al-Atîr. Parece evidente, en primer lugar, que el relato de al-Nuwayrī procede íntegramente del de Ibn al-Ațìr. Hay pequeñas variaciones, pero pueden deberse a la mano de al-Nuwayrī o bien a que éste conoció una versión de Ibn al-Atīir ligeramente diferente de la que nos ha llegado a través del Kämil. En cualquier caso, es evidente que entre el Kämil y la Nihāya de al-Nuwayrī hay una indudable relación de dependencia. Respecto al relato de Ibn Jaldūn, guarda también una estrecha relación con la versión de Ibn alAțîr, aunque el primero pudo resumir su texto o bien conocer otro ligeramente diferente. Ibn Jaldūn no indica la fecha del suceso del Foso pero deducimos que sitúa el acontecimiento hacia el año 191 porque la noticia inmediatamente anterior es el suceso del Arrabal de Córdoba, con fecha del año 190 (805-806), mientras que la siguiente noticia fechada, el cerco de Tortosa por los francos, se menciona en el año 192 (807-808). Un detalle curioso de este relato es que el texto no da a entender que la petición de auxilio del gobernador de la Marca Superior estuviera planeada por el emir, detalle que sí aparece de forma explícita en Ibn al-Ațir, pero puede deberse simplemente a que Ibn Jaldūn estaba resumiendo la narración. Además, es la única versión donde se utiliza la palabra مدينة para designar la construcción levantada por 'Amrūs; el resto de los autores emplea los términos قلعة , قصر ,قصبة o, simplemente, بناء.

Para completar esta segunda familia de textos, debemos citar también a dos autores orientales. El primero, al-Dahabī, presenta un relato breve en el que narra cómo el emir al-Ḥakam decide encomendar el gobierno de la ciudad a 'Amrūs después de que los toledanos apresaran a su gobernador y lo expulsaran. La población levanta una fortaleza siguiendo el consejo de 'Amrūs y cuando, más tarde, el hijo del emir sale en expedición, los toledanos le invitan a que entre en ella. Se celebra un banquete y se hace entrar a los invitados por una puerta, haciendo ver que saldrían por otra. En el interior del recinto son decapitados, muriendo cerca de cinco mil de ellos. Con este breve texto, en el que no se menciona la fosa, al-Dahabī está resumiendo otro relato. En este caso, sí se especifica la fuente, que, a pesar de que en la edición consultada aparece como Ibn Muzyan, es evidente que se trata de Ibn Muzayn, autor andalusí del s. XI del que apenas tenemos datos.

Al-Dahabī no fecha este suceso, pero da cuenta de él después de su crónica de la revuelta del Arrabal de Córdoba, que sitúa en el año 202 (818). Según su versión, por tanto, el suceso del Foso tuvo lugar en una fecha posterior. En todo caso, el contenido de esta versión guarda muchas similitudes con este segundo grupo de textos, sin que se pueda establecer una relación directa con alguna de las fuentes que manejamos. Así, el relato de al-Dahabī debe de proceder de una tradición oriental que pudo tener su origen en la versión de Ibn al-Qūtịya. 
Al-'Umarī, por su parte, transmite un extenso texto, tomado de Ibn Zāifir, que debemos asociar también a esta familia de versiones ${ }^{30}$. Comienza con un fragmento introductorio que describe la inexpugnabilidad de la ciudad, su río, el puente y las fortalezas circundantes. Relata después que el emir al-Ḥakam nombra gobernador de la ciudad a 'Amrūs, quien, tras conseguir la confianza de los toledanos, construye una fortaleza para él y la tropa en el centro de la ciudad. El emir envía más tarde a su hijo 'Abd al-Raḥmān al frente de una expedición dirigida a la Marca Superior y, al pasar por Toledo, la población le invita a entrar en la ciudad. El monarca le hace llegar entonces la noticia de que ha circuncidado a sus hermanos más pequeños en Córdoba y desea que prepare un banquete en Toledo con ese motivo, al que acudirán los toledanos. Durante el festejo, serán asesinados y arrojados a una fosa que hay en el interior del recinto fortificado. A mediodía, uno de los invitados sospecha que algo grave ocurre y recuerda las palabras de Quss b. Sā'ida que ya conocemos. Al percatarse del vapor de sangre procedente del alcázar, alerta a los demás, pero ya es demasiado tarde y los soldados caen sobre ellos. Se recuerda, finalmente, el defecto en la vista del príncipe 'Abd al-Raḥmān.

Como podemos comprobar, hay en esta versión muchos datos que ya conocemos a través de otros textos. El hilo argumental es el mismo que articula el relato de Ibn al-Qūtiyya del Tárìj iftitiăh al-Andalus, aunque las diferencias formales entre ambos impiden pensar que éste sea su fuente. El primer fragmento, dedicado a la descripción de la ciudad, también nos recuerda el primer párrafo de la versión de al-Qubbašī — los dos hablan de la posición dominante de la ciudad y de la duración de los cultivos y afirman que los toledanos tendían a la sublevación-, pero no procede de él. Igualmente, debe de haber alguna relación entre este texto y el final del relato de Ibn al-Qūtịyya que Ibn Ḥayyān transmite, puesto que en ambos encontramos la cita de Quss b. Sā'ida, que no aparece en ninguna otra fuente. Aunque las similitudes son, en su mayoría, comunes a estos tres textos que acabamos de citar, no podemos pasar por alto que al-'Umarī también incorpora un dato que sólo está presente en una de las versiones y que ésta, paradójicamente, no guarda relación directa con ninguna de las dos familias de textos que venimos describiendo. Se trata del relato de 'İsà al-Rāzī que aparece en el M2-b y que, hasta ahora, no he citado en este estudio historiográfico. Ambos autores mencionan la circuncisión de los hijos del emir como excusa para celebrar un banquete en Toledo. A la vista de todos estos datos, es evidente, en primer lugar, que la versión de al-'Umarī entronca con el relato de Ibn al-Qūtịya. Es posible que el damasceno esté transmitiendo un texto del autor andalusí en el que se mencionaba la circuncisión y la cita de Quss b. Sā'ida que no es el del Tảīj iftitāh al-Andalus y que se asemejaría al de al-Qubbašĩ.

30 Véase el texto árabe y su traducción, así como indicaciones sobre la fuente de al-'Umarī, en M. Crego Gómez, "La Jornada del Foso de Toledo según Ibn Fạ̣l Allāh al-'Umarī. Edición y traducción”, Al-Andalus-Magreb. Estudios árabes e islámicos, 14 (2007), pp. 269-275. 
Finalmente, sólo resta mencionar los textos de Ibn al-Jațīb y del Dikr bilād al-Andalus. El autor granadino incorpora en su Kitāb a'māl al-a'lām una breve noticia alusiva al Foso según la cual el emir al-Ḥakam o su hijo pasaron cerca de Toledo y, con ese motivo, se celebró un banquete en la ciudad. Los toledanos acudieron al alcázar y allí fueron asesinados. La matanza, que acabó con cinco mil trescientos de ellos, fue descubierta por uno de los notables al percatarse de que el vapor procedía de la sangre y no de la comida del festín. En este texto no se cita a 'Amrūs ni tampoco se menciona la fosa, pero debe ser incluido dentro de esta familia de textos, pues recoge muchos elementos propios de ella. Además, guarda relación con el relato de Ibn al-Qūṭiyya del Tárij, con el que coincide al hablar del hijo del emir, de la expedición y el vapor de la sangre, e incluso del mismo número de víctimas. Sin embargo, si Ibn al-Qūtịya es la fuente última de Ibn al-Jațiib, su relato le llegó muy resumido y extractado y desconocemos a través de qué fuentes le fue transmitido. Únicamente hay un detalle que difiere del resto de las versiones y es que aquí el suceso está fechado en el año 181. Por otro lado, las breves líneas que el $\underline{D} i k r$ - la versión más tardía de todas- dedica a la «Jornada del Foso» deben de estar emparentadas con una versión de Ibn al-Qūtiyya que no es la del Tárij pero que no conocemos con exactitud; debe de ser una versión que guarda relación, por un lado, con la de al-Qubbašĩ e Ibn al-Qūtiyya del M2-b, con los que el Di ikr coincide en la fecha y en la mención de la advertencia que hace uno de los toledanos y, por otro, con los relatos de Ibn al-Atīir y al-Nuwayrī, con los que comparte también la fecha y un detalle curioso: son los tres únicos textos que aluden al banquete empleando el término وليمة. No obstante, resulta difícil establecer el origen de este pequeño fragmento porque, además, incluye elementos que también están presentes en los textos de al-Rāzī e Ibn 'Iḍārīi, como el número de víctimas.

La versión de 'Īsà al-Rāzī que ahora conocemos a través del M2-b no ha sido incluida, como ya he dicho, en ninguno de los dos grupos que acabo de describir. Lo cierto es que no guarda relación directa con los relatos de su padre, Aḥmad al-Rāzì, y de Ibn al-Qūṭiyya, los autores más próximos a su tiempo. Tan sólo coincide en un dato con al-'Umarī, como ya se ha señalado, y es el de referir la circuncisión de los hijos del emir al-Ḥakam. Obviamente estas dos familias de textos, así como el relato atribuido a 'İsà al-Rāzī, deben de proceder de una misma tradición, de una fuente primera que desconocemos.

\section{CONCLUSIONES}

En definitiva, después de llevar a cabo el cotejo textual completo de las versiones conocidas acerca de la «Jornada del Foso» (véase al final de este trabajo el esquema simplificado de las relaciones entre las fuentes), es posible distinguir con claridad dos familias de textos. Una de ellas estaría formada por los relatos de Aḥmad al-Rāzī e Ibn 'Iḍārī y por las noticias fechadas en el año 181 de Ibn al-Ațîr, al-Nuwayrī e Ibn Jaldūn. Estos dos últimos autores prescinden, en este 
caso, de los datos referidos al foso y a la matanza. El segundo grupo, compuesto por un mayor número de textos, generalmente muy extensos y minuciosos en el detalle, tendría como origen un relato de Ibn al-Qūṭiyya, del que se conservaron, al menos, dos versiones distintas.

TEXTOS DEL MS. M2-b

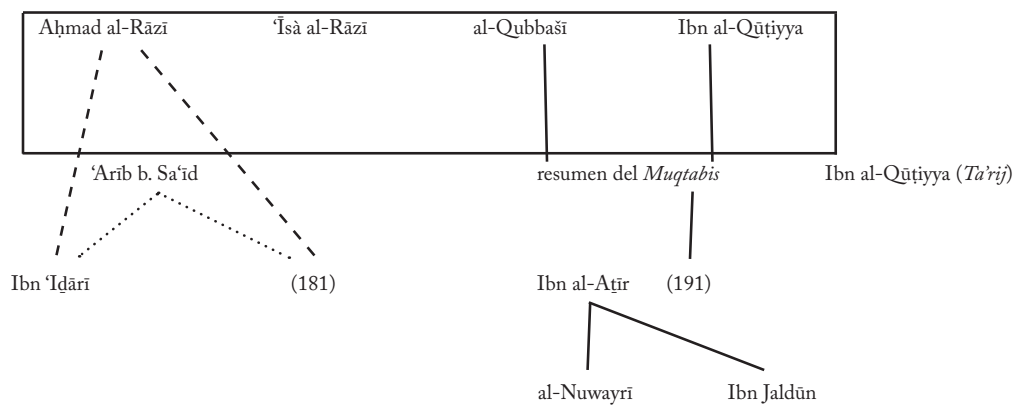

Transmisión directa

Transmisión indirecta

Transmisión no confirmada

\section{FUENTES ÁRABES}

'Arīb b. Sa'īd, La crónica de 'Arīb sobre al-Andalus, trad. y est. J. Castilla Brazales, Granada, Impredisur, 1992.

Al-Dַhabī, Siyar a 'ām al-nubalä’,, Beirut, 1986.

Dikr bilāed al-Andalus. Una descripción anónima de al-Andalus, ed. L. Molina, Madrid, 1983.

Ibn al-Ațîr, Al-Kämil fì l-ta'rīj, Beirut, 1979.

Ibn Ḥārit al-Jušanī, Ajbār al-fuqahä’ wa-l-muhaddițīn, ed. y est. Ma L. Ávila y L. Molina, Madrid, 1991.

Ibn Hayyān, Muqtabis II. Anales de los Emires de Córdoba Alhaquém I (180-206 H/796822 J. C.) y Abderramán II (206-232/822-847), ed. fac. de un ms. árabe de la R. A. H. (Legado Emilio García Gómez) J. Vallvé Bermejo, Madrid, R.A.H., 1999 (M2-b).

-,Al-sifr al-țan̄̄ min Kitāb al-Muqtabas, ed. M. 'A. Makkī, al-Riyad, 2003.

—, Crónica de los emires Alhakam I y Abdarrahmān II entre los años 796 y 847 [Almuqtabis II-1], trad., notas e índices M. 'A. Makkī y F. Corriente, Zaragoza, Instituto de Estudios Islámicos y del Oriente Próximo, 2001.

-, Al-Muqtabas min anbä' abl al-Andalus li-bn Hayyān al-Qurțubì, ed. M. 'A. Makki, Beirut, 1973 (M2-c).

Ibn 'Iḍārī, Histoire de l'Afrique du Nord et de l'Espagne musulmane intitulée 'Kitāb alBayān al-Mugrib' par Ibn 'Idārì al-Marrākušì et fragments de la chronique de 'Arīb d'après l'édition de 1848-1851 de R. Dozy et de nouveaux manuscrits, ed. G. S. Colin y É. Lévi-Provençal, Leiden, 1948-51, (Bayān II).

Ibn Jaldūn, Kitäb al-'ibar, Beirut, 1867.

Ibn al-Jațīb, Kitāb a'māl al-a làm. Histoire de l'Espagne musulmane extraite du 'Kitāb a'māl al-a'lām', ed., introd. e índices É. Lévi-Provençal, Rabat, 1934. 
Ibn al-Qūtịya, Historia de la conquista de España por Abenalcotía el Cordobés, ed. y trad.

J. Ribera, Madrid, 1926.

Al-Nuwayrī, Nihāyat al-arab fì funūn al-adab, El Cairo, 1980.

Al-'Umarī, Routes torwards insight into the capital empires. Masālik al-abșār fì mamālik alamșār, ed. F. Sezgin, Frankfurt am Main, 1988.

Al-Ŷāhiz, Al-Bayān wa l-tabyīn, El Cairo, s.d.

\section{REFERENCIAS BIBLIOGRÁFICAS}

Ávila, Ma. L., "La fecha de redacción del Muqtabis", Al-Qanțara, V (1984), pp. 93-108.

Crego Gómez, M., Toledo en época Omeya (s. VIII-LX), Toledo, Diputación de Toledo, 2007.

—, "La Jornada del Foso de Toledo según Ibn Faḍl Allāh al-'Umarī. Edición y traducción”, Al-Andalus-Magreb. Estudios árabes e islámicos, 14 (2007), pp. 269-275.

Marín, M., "Nómina de sabios de al-Andalus (93-350/711-961)", E.O.B.A., I (1988), pp. 23-182.

Molina, L., "Un relato de la conquista de al-Andalus", Al-Qunțara, XIX (1998), pp. 39-65.

Pellat, C., "Kuss b. Sāiida”, EI², V, pp. 532-533.

Viguera, Ma. J., Aragón musulmán. La presencia del Islam en el valle del Ebro, Zaragoza, 1988 (2a ed.).

Nombre del autor: María Crego Gómez

Dirección-e: mcregom@upo.es

Dirección postal: Departamento de Filología y Traducción, Universidad Pablo de Olavide de Sevilla, Ctra. de Utrera, km. 1, 41013 Sevilla

Fechade recepción: 10/03/2012

Fecha de aceptación: 28/03/2012 
